\title{
Psychological Guidance of Public Welfare Activities on Latent Depressed Population
}

\author{
Yingqun Wang, Yu Wang \\ Foreign Languages School, Changchun University of Technology, China
}

Keywords: Psychology; Depression; Public Welfare.

\begin{abstract}
Melancholia, also known as depressive disorder is a common psychological disease mainly featured by notable and lasting depressed mood. More and more people living under stress in life or environment are suffering from melancholia as a result of the increasingly fierce social competition and life pressure; the more frightening is that many people have ended up committing suicide. This paper focuses on the cases of imperfect understanding yet rather more misunderstandings to melancholia. The purpose is to adopt a positive attitude to encourage the establishment of commonweal organizations, vigorously promote the development of public activities so as to call for more people to cast aside prejudice for depression.
\end{abstract}

\section{Introduction}

Melancholia has become the world's fourth disease. During the Mid-autumn Festival, 2016, the 28-year-old singer and actor Qiao Renliang (Kimi) died an accidental death. It was melancholia that made this young handsome boy end his very life which was supposed to be blooming. For a moment, melancholia was concerned again by the entire society. This article is aimed at analyzing the guidance effects of public welfare activities on the latent depressed population, in the hope of calling for the care and love of the public for patients with depression by means of public welfare activities so as to help them get rid of the disease and join efforts to establish a harmonious and healthy society.

\section{Public Welfare Activities and Latent Population with Melancholia Symptoms}

\section{(1) Concept of latent Depressed Population}

Clinically speaking, people with two of the above symptoms can be considered to suffer from melancholia. These people also show obvious manifestations in clinical scale, for instance, China takes the SDS standard mark $\geq 50$ in the Self-Rating Depression Scale (SDS) as the depressive symptoms. The latent depressed population refers to those who carry some characteristics of clinical diagnosis of depression yet haven't reached or approach the diagnostic criteria; mostly they are aware of their life being influenced and willing to make changes of it.

\section{(2) Public Welfare Activities}

Public activities refer to the practical activities for public relations with thematic or phased public welfare undertakings. The propaganda of public activities is generally promoted by enterprises with good economic profits or social celebrities to focus on the special social groups or social hot topics and actively advocate certain social undertakings and form the favorable social conducts.

A. Purpose of Public Activities

Generally speaking, it establishes some carriers by certain organizations or influential figures in certain forms to call for the public attention on a certain social issue so as further to regulate our behaviors with criteria in accordance with the social welfare or spread love with our practical actions. It advocates common participation, attention on social hot issues and concern for special groups to form the healthy social atmosphere and advocate the favorable social conducts.

The purpose of developing public activities to show concern for the depressed population is to improve the public consciousness of psychological health, propose people's optimistic and positive attitude to deal with stress in life, establish the healthy and happy way of life; it also works on getting more people come to understand melancholia, care about the patients with depression around us, 
listen and understand them attentively so as to help them shake off depression and live their lives in the sunshine.

\section{B. Form of Public Activities}

Public activities aiming at the depressed population can be carried out in various forms, for instance we can develop a series of recreational and sports activities or lectures and propaganda for various knowledge, public sand play activities for psychological service, television public welfare advertisements etc. In addition, the Internet shall be made good use of to propagate the public activities. We can popularize knowledge about melancholia to the society by means of online media i.e. public discourse, QQ group, wechat public account as well as Sina Weibo and Baidu Post Bar so that more people will get involved to understand this disease and join their efforts to promote the development of melancholia welfare.

C. Significance of Public Activities

Social public activities are the continuation of China's fine tradition and underlying demand to build the harmonious socialist society. Melancholia welfare activities enable the social compassion figures to join hands in exploring how to make melancholia valued by the whole society and how to help the patients as well as their families more effectively, hold up a protective umbrella for the patients so that their "damped" hearts could embrace the sunshine of life soon. In the meanwhile, it also brings us the long-term happiness and satisfactions to participate in the public societies. We are capable of reviving and deepening our extraordinary public traditions and making the society warmer and more harmonious if we give full play to the spirit of "One for all and all for one", enhance the consciousness of social responsibility and foster our consciences.

\section{Characteristics of Number and Stratified Distribution of Latent Depressed Population}

\section{(1) Number of Latent Depressed Population}

According to WHO, there are 340 hundred million patients with depression throughout the world. Melancholia has become the world's fourth disease and might be the second disease only next to heart disease for mankind in 2020.

There are studies showing that hypomania and depression have something to do with vitality, creativity and charm. Such gene could bring forth natural

Advantages to the individuals; therefore, the US psychologist Sperrle once said: "This disease always attacks those who are most ambitious, creative and conscientious." Quite a lot of celebrities in history i.e. Newton, Darwin, Lincoln and Churchill as well as many writers i.e. Echo (Sanmao), Hemingway, J·K·Rowling and the modern celebrities like Cui Yongyuan (CCTV host), Han Hong (female singer), Yang Kun (male singer) and Zhou Huajian (male singer) were haunted by melancholia.

\section{(2) Psychological Guidance of Public Welfare Activities on Latent Depressed Population}

\section{A. Develop hobbies and interests and help them rebuild the confidence}

Due to the long-standing anxiety and inferiority, some patients have lost faith in themselves hence self-denial and lack of sense of existence and pride. It would get the patients involved and help them relieve their pressure, re-examine themselves in cultivating interests to seek the positive energy and build confidence which they have lost for long by carrying out some literary and artistic public activities like painting competition, calligraphy exhibition and music communication meting.

The Hong Kong actress Zheng Xiuwen (Sammi Cheng) once suffered from melancholia. Mei Yanfang (Anita Mui)'s death in 2003 was a great shock to her and it was during that period of time that she was hopelessly bogged down into depression. She made up her mind to start with a new life after being tortured for long. She would pick up the paintbrush to paint and feel the artistic breath every time when she was immersed in sadness and could not carry on; she also started cooking for herself and enjoyed the delights came along with fine food. It took her as long as three years to defeat that depressed version of herself and retake her life.

\section{B. Do more physical exercises and open up the blocked hearts}

Doing exercise is a pretty straightforward method to treat depression. We can get the patients out of the house to run, swim and play basket so as to release themselves in sweat and work off their 
depression by holding some public activities such as "Nationwide Fitness" and "Travel Hand in Hand" etc. In this way they could not only do exercise but also make the mind-liked friends so that they could be more sociable and better integrated into society.

In the year 2005, after releasing his new album 2008, Yang Kun (male singer) went in low spirits. $\mathrm{He}$ had to handle the termination with company amongest a great number of invitations for commercial performance. Undoubtedly he came down with melancholia. Fortunately, he learned to find regularities out of the irregular life of celebrities after he got sick, he ate and slept on time, went for active social contact and walked to the gymnasium and spent the entire afternoon there riding bicycle, running, swimming and doing exercise with equipment. He got himself break into a sweat every day and finally saved himself out of the tortures of depression thank to the long-term exercise and positive attitude.

\section{(3) Build the bridge of communication and wipe out the depression}

No one is fond of staying together with someone grave and pessimistic for long. However for the patients with depression, your occasional concern, companion or communication might be the hand that pushes them to re-connect with the real world.

Most patients with depression always refuse to communicate with others hence develop the isolated characters for various inner ambivalence. We could develop some communication forums so that families and friends could get involved and the patients with depression would open up their hears to reveal their inner contradictions; in the meanwhile, companion and encourage from families could help them relieve the pressure and rekindle their passion for life.

\section{(4) Discard prejudice against depression and comfort the injured souls}

The great power of love, wisdom and willpower could help us get out of the city of despair even depression might be the demons that mankind can never escape from. However according to the specific situation of the current society, most people would try best to avoid the patients with depression worrying that they might commit suicide once being accidentally touched with the tender spots by them. So to them patients with depression seem to be a time bomb that might be triggered anytime. It is just such prejudice and discrimination from the entire society that has done the largest harm to patients with depression. By means of public activities, we could popularize knowledge of melancholia among the public and correct the misunderstandings about melancholia, so that the society would show more support, concern and care but less criticism, censure and indifference to build a favorable social atmosphere and make melancholia less horrible.

\section{Conclusion}

As an unawakened silent killer in the world, melancholia has been silently eating up the will to live of each patient. It is fearful that so many patients with depression have been reported time and again to commit suicide in the recent years. The young lives were stolen from us one after another for depression, only leaving a sigh behind. Poor quality of sleep, emotional depression, anxiety, being pessimistic and disappointed, anyone of us might run across melancholia, not mention that with the faster and faster pace of the modern society, we should pay more attention to the increasingly widespread melancholia. However, as extremely psychological disorder, there are truly rare domestic commonweal organizations for melancholia. In this situation, we have to start over to understand melancholia, reduce the online "linguistic violence" and "moral kidnapping" so as to join efforts to build a healthy and harmonious society as a big family and help more patients with depression get rid of it and recover hope in life.

\section{Acknowledgments}

The authors would like to give their thanks to Jilin Education and Science Institute (No. GH16168, An interpretation of the causes of college students' learning disability and a study of the corresponding corrective strategies) for their support. 


\section{References}

[1]. Han Lintao How Many Melancholics are there actually in China [J]. Health Times; 2003;

[2]. Melancholia--As Common as Catching A Cold Maternal and Child Health. 2003 (6)

[3]. Wang Gang. Some Figures about Melancholia, China Pharmaceutical News 2007. 12 